\title{
Neoplastic lesions of endocrine cells in the gastrointestinal tract: ten evolving principles as a basis for clinical understanding
}

This article was published in the following Dove Press journal:

Gastrointestinal Cancer:Targets and Therapy

27 December 2012

Number of times this article has been viewed

\author{
Ben Lawrence ${ }^{1,2}$ \\ Malcolm Anderson ${ }^{3}$ \\ Simon Schimmack' \\ Michael Findlay ${ }^{2,3}$ \\ Mark Kidd' \\ Irvin Modlin' \\ 'Department of Surgery, Yale \\ University School of Medicine, \\ New Haven, CT, USA; ${ }^{2}$ School of \\ Medical Sciences, Faculty of Medical \\ and Health Sciences, University \\ of Auckland, ${ }^{3}$ Department of \\ Oncology, Auckland District Health \\ Board, Auckland, New Zealand
}

Correspondence: Ben Lawrence Gastrointestinal Pathobiology Research Group, Department of Surgery, Yale University School of Medicine, 310 Cedar Street, PO Box 208602, New Haven, CT 06520-8062, USA Email b.lawrence@auckland.ac.nz

\begin{abstract}
Timely and appropriate diagnosis and treatment of patients with gastroenteropancreatic neuroendocrine neoplasms is a difficult clinical endeavor. The field is particularly dynamic, not only in terms of expanding therapeutic options, but in the classifications and biological principles that underpin good decision-making. Acknowledging the confusion created by past changes and the inevitability of future development, we combine our clinical experience with a review of the literature to frame the current understanding of gastroenteropancreatic neuroendocrine neoplasms in terms of a set of principles that have stabilized in the midst of this change. Firstly, we present five principles that guide classification of neuroendocrine neoplasms; specifically principles of prognostic classification, mechanisms of tumorigenesis, undiagnosed disease burden, clues regarding genetic etiology, and typical clinical presentation. Secondly, we offer five clinical principles upon which to build a therapeutic strategy. Specifically, these treatment principles include the separation of options by tumor cell differentiation, and the site of the primary lesion in well differentiated tumors. Chromogranin A is a moderately useful biomarker. Treatment should only be considered by clinicians in a multidisciplinary team, and in the face of multiple potential therapeutic options without a supporting evidence base, clinical trial enrolment remains imperative. Therefore, we provide a current synopsis of classification of gastroenteropancreatic neuroendocrine neoplasms, and their etiology, clinical presentation, and management in a novel framework of ten relatively stable principles.
\end{abstract}

Keywords: gastroenteropancreatic neuroendocrine neoplasms, neuroendocrine tumors, epidemiology, molecular targeted therapy, histopathology, grading, staging, carcinoid, tumorigenesis

\section{Introduction}

Neuroendocrine neoplasms exhibit marked heterogeneity in terms of location and malignant potential. ${ }^{1}$ Neuroendocrine neoplasms arise wherever neuroendocrine cells exist in epithelial linings, most commonly from the epithelium of the gastrointestinal tract or the pancreas, and are labeled gastroenteropancreatic neuroendocrine neoplasms. ${ }^{2}$ The term neuroendocrine has been retained because the cells from which gastroenteropancreatic neuroendocrine neoplasms arise have a combined neural and endocrine phenotype; for example, enterochromaffin cells demonstrate neurite outgrowths extending from their base which interact with neural tissue in the gut, yet they also have an endocrine function and secrete measurable levels of serotonin. ${ }^{3}$ Both neural and endocrine functions are required to perform their primary function, which is control of gut motility and digestion. Therefore, this epithet "neuroendocrine" has necessarily persisted.

Such difficulties in nomenclature have plagued the field, but even more confusion has arisen due to multiple classification systems, updates following the introduction 
of new terminology, and the recycling of old terminology into new classifications with new meanings. ${ }^{4}$ In addition, the tumor is rare and heterogeneous in its course, making appropriate clinical exposure the exception for the majority. ${ }^{5-8}$ Further, many different therapeutic interventions have been reported. Thus, the clinician is faced with a cancer that they might not be able to name, that they will seldom see, that will follow an unknown course, and that could be treated with various combinations of therapy from various medical and surgical specialties.

This paper applies a clinical perspective to recent developments in classification, epidemiology, molecular biology, and clinical trials to integrate clinical decisionmaking. We combine the themes that are emerging to define principles to guide any clinician faced with a new patient with a neuroendocrine neoplasm. Therefore, we introduce the definitions, etiology, clinical presentation, and current therapeutic strategies for non-neoplastic and neoplastic proliferative lesions of endocrine cells of the gastrointestinal tract in terms of a series of principles that might provide some stability in this constantly changing landscape.

\section{Multiple previous classification systems are now increasingly confluent and emphasize grade, differentiation, and stage}

Totipotent stem cells in gastrointestinal crypts will differentiate into typical nonsecretory epithelial cells or several secretory phenotypes (see Figure 1). One class of secretory epithelial cells in the gastrointestinal lumen and pancreas are neuroendocrine cells. These neuroendocrine cells and their precursors give rise to a variety of malignancies currently labeled "neuroendocrine neoplasms". ${ }^{2}$ It has been suggested that the poorly differentiated carcinomas derive from less mature precursors, and well differentiated tumors derive from more mature, committed neuroendocrine cells. ${ }^{9}$ Perhaps, due to the existence of a common precursor, gastroenteropancreatic neuroendocrine neoplasms can occur associated with an adenocarcinoma in the same location, for example, in the pancreas. ${ }^{10}$ Gastroenteropancreatic neuroendocrine neoplasms have proved difficult to classify clinicopathologically, leading to multiple classification schemes over the past several decades, creating diagnostic confusion amongst pathologists and clinicians (Table 1). The reader should note the shifts in principles of categorization; that these lesions were initially all considered benign ${ }^{11}$ but are now all considered malignant, ${ }^{2}$ that

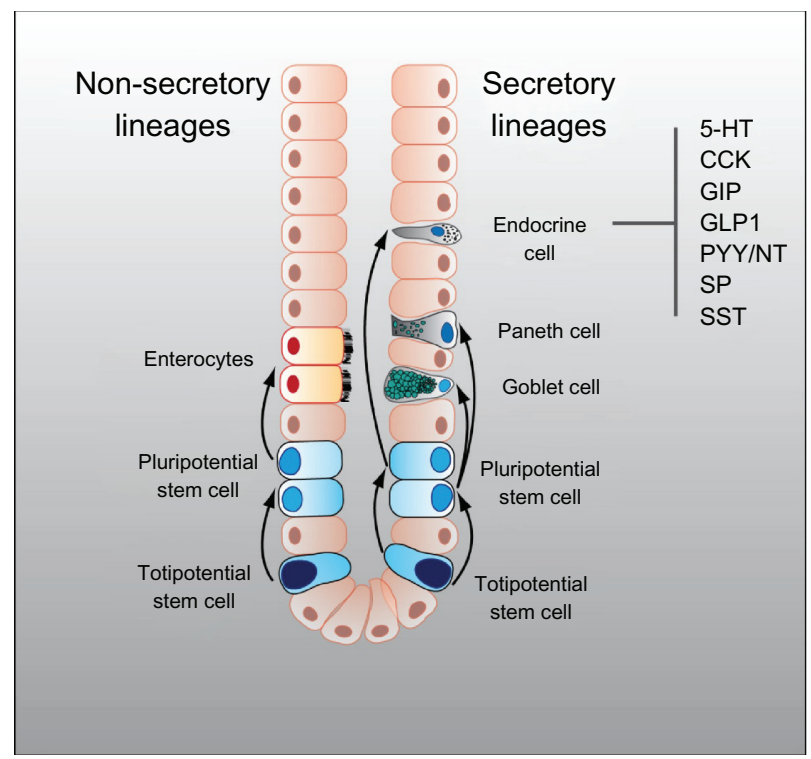

Figure I Proposed epithelial cell lineage showing a common precursor for secretory and nonsecretory cells.

With kind permission from Springer Science + Business Media: Schimmack S, Svejda B, Lawrence B, Kidd M, Modlin IM. The diversity and commonalities of gastroenteropancreatic neuroendocrine tumors. Langenbecks Arch Surg. 201 I;396(3): 273-298.

broad embryological groupings ${ }^{12}$ have been replaced by organ-specific diagnoses ${ }^{13}$ (and further subclassification in gastric neuroendocrine neoplasms ${ }^{14}$ ), the recent supplementation of differentiation by proliferative index (now the defining measure of "grade"), ${ }^{15}$ and the recent validation of a TNM staging system ${ }^{16}$ similar to other gastrointestinal malignancies. The current classification is now in accord with other cancers with classification by grade, differentiation, and stage.

The current prognostic classification of gastroenteropancreatic neuroendocrine neoplasms is most recently summarized in the World Health Organization recommendations. ${ }^{2}$ Grade is synonymous with proliferation index. NET-G1 is a low-grade lesion with a $\mathrm{Ki}-67 \leq 2 \%$ and/or a mitotic rate of $<2$ per 10 high-powered fields. NET-G2 is an intermediate-grade lesion with a Ki-67 of 3\%-20\% and a mitotic count of 2-10 mitoses per 10 high-powered field. NET-G1 and NET-G2 are well differentiated, whereas neuroendocrine carcinoma lesions are poorly differentiated and have a Ki-67 $>20 \%$ and/or a mitotic count $>10$ per 10 high-powered fields. These criteria are nearly identical in the most recent European Neuroendocrine Tumor Society ${ }^{2}$ and North American Neuroendocrine Tumor Society recommendations ${ }^{17}$ It should be noted that these definition cut points are arbitrary and that tumors within these groups may have differing behaviors. Furthermore, assessment of $\mathrm{Ki}-67$ is complicated by intratumoral heterogeneity and 


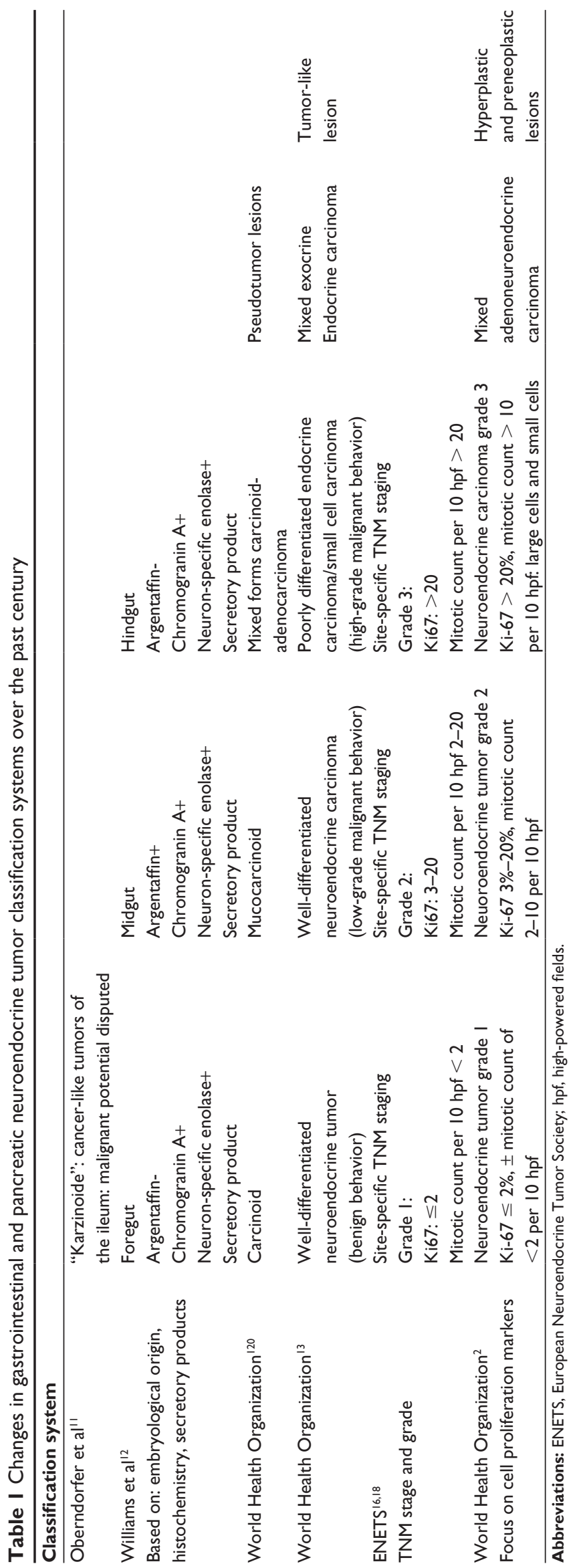

subject to pathologist-dependent variability. TNM staging has been suggested, ${ }^{16,18}$ and undergone initial validation such that the $\mathrm{T}$ staging (by size and degree of luminal wall invasion), $\mathrm{N}$ staging (by the presence or absence of lymph node involvement), and $\mathrm{M}$ staging (based on the presence of distant metastases) appear to contribute to prognostication on initial inspection. ${ }^{19,20}$ In keeping with other tumor types, high-grade and metastatic lesions have a worse prognosis; however, there is marked variability within primary tumor sites. ${ }^{21}$

\section{Tumorigenesis by malignant} progression from hyperplasia, to dysplasia, to neoplasia occurs in a portion of foregut lesions, but the majority lack etiological explanation

Preneoplastic states have been formally acknowledged in the recent World Health Organization classification ${ }^{2}$ (see Table 1). Specifically, the transition from hyperplasia to dysplasia to neoplasia is described in gastric neuroendocrine neoplasms (type 1 and 2), duodenal neuroendocrine neoplasms, and pancreatic neuroendocrine neoplasms, ${ }^{22}$ but is rare in the remainder of the gut. ${ }^{23}$ This observation is important because it allows a guess at etiology, which is only well defined in the stomach ${ }^{24}$ (Figure 2). Type I tumors occur in the presence of achlorhydria (eg, due to atrophic gastritis) which results in compensatory elevation in gastrin which drives enterochromaffin-like cell hyperplasia, dysplasia, and ultimately neoplasia. Type 2 lesions occur in the presence of an elevated gastrin concentration secondary to secretion by a gastrinoma, often causing Zollinger-Ellison syndrome, and occurring in the setting of multiple endocrine neoplasia type 1. Type 3 lesions occur in the absence of a gastrin drive and, as for the majority of gastroenteropancreatic neuroendocrine neoplasms, the cause remains unknown. ${ }^{25}$ The appearance and prognosis of each type is distinct and ranges from typically small and multifocal type 1 gastric neuroendocrine neoplasms with excellent prognosis, through to single large type 3 lesions which follow an aggressive course. Therefore, this model of neuroendocrine neoplasm etiology suggests that other well differentiated gastroenteropancreatic neuroendocrine neoplasms with low proliferative indices where the progression from hyperplasia to dysplasia is observed (thus akin to type 1 and 2 lesions) might also undergo malignant transformation due to the presence of an endogenous growth factor. However, to date, this progression has only been observed in sites of active inflammatory bowel 

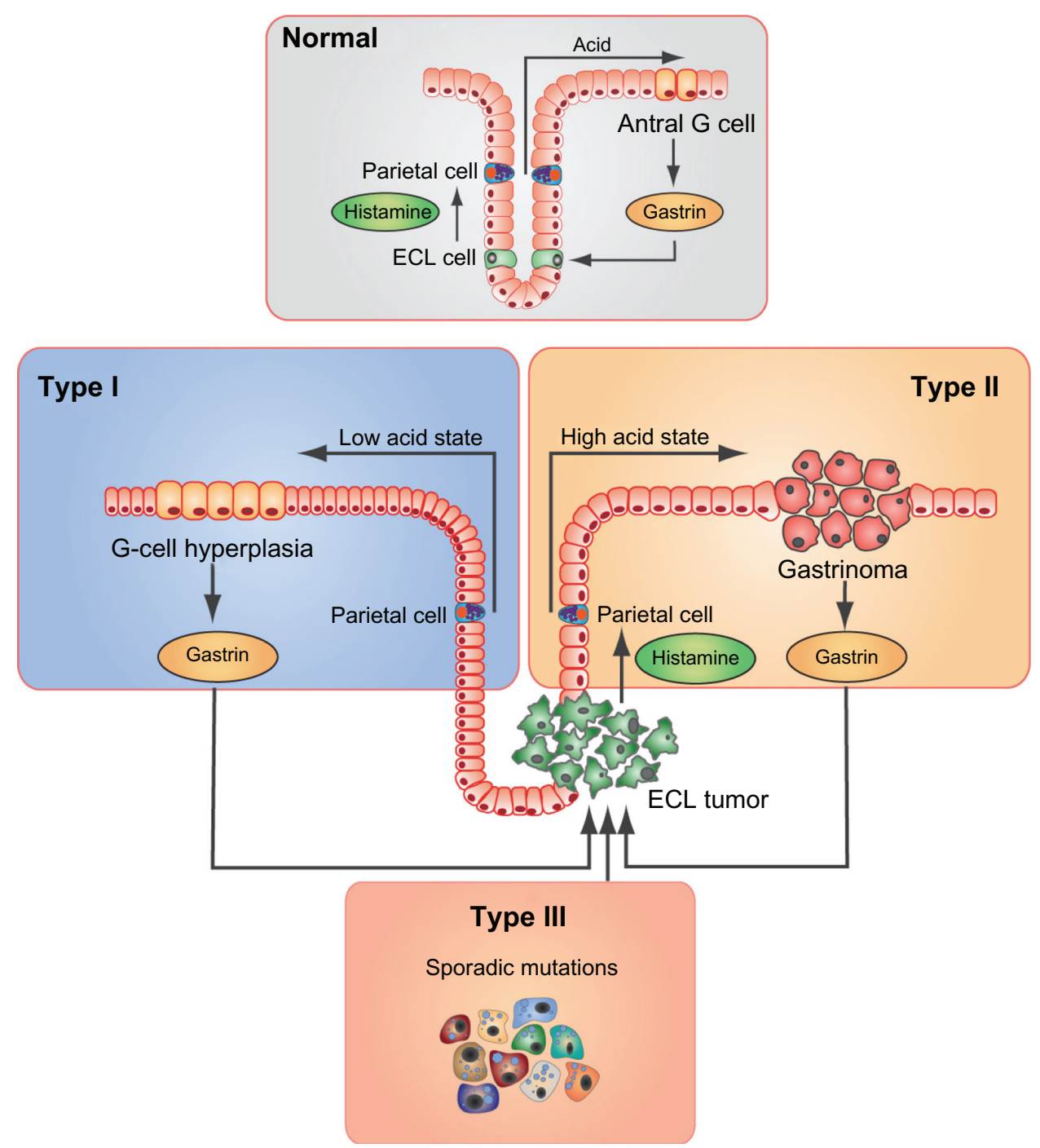

Figure 2 Tumorigenesis in gastric neuroendocrine neoplasms.

Notes: In the normal setting, G cells secrete gastrin which drives production of histamine by enterochromaffin cells, which in turn encourages secretion of acid by parietal cells. In type I gastric neuroendocrine tumors, the parietal cells fail to produce acid, resulting in compensatory $\mathrm{G}$ cell secretion of gastrin, which drives enterochromaffin cell transition from hyperplasia to dysplasia to neoplasia. Despite this positive feedback loop, the low acid state persists due to pre-existing parietal cell atrophy. In type 2 gastric neuroendocrine tumors, gastrin secretion is autonomous due to gastrin secretion from a gastrinoma. In type 3 gastric neuroendocrine tumors, the cause of malignant transformation is unknown.

With kind permission from Springer Science + Business Media: Schimmack S, Svejda B, Lawrence B, Kidd M, Modlin IM. The diversity and commonalities of gastroenteropancreatic neuroendocrine tumors. Langenbecks Arch Surg. 201 I;396(3):273-298.

disease in the small intestine and colon, although the driver of tumorigenesis in this setting has not been elucidated.

\section{Majority of lesions are never diagnosed during life and do not contribute to mortality}

It is useful to conceive neuroendocrine neoplasms as common tumors, but not tumors that are commonly diagnosed during life. Autopsy studies suggest that approximately $1 \%$ of people will have a detectable gastroenteropancreatic neuroendocrine tumor at the time of death, although this is seldom the cause of death. A large series $(n=16,294)$ in Malmo, Sweden, ${ }^{26}$ showed that $1.11 \%$ of patients who underwent autopsy had a gastroenteropancreatic neuroendocrine neoplasm, and a similar study in Hong Kong ${ }^{27}$ found that $0.1 \%$ of patients had a pancreatic neuroendocrine neoplasm. These two figures are complementary because pancreatic neuroendocrine tumors make up approximately $10 \%$ of all gastroenteropancreatic neuroendocrine neoplasms in registry data, such as in the Surveillance, Epidemiology and End Results database. ${ }^{28}$ These autopsy results indicate a prevalence of approximately 1110 per 100,000 persons, which is considerably more than the prevalence calculated from the registry data (35 per 100,000). ${ }^{29}$ This suggests that approximately $3 \%$ 
of gastroenteropancreatic neuroendocrine neoplasms that are present are actually detected during life, and that the vast majority of gastroenteropancreatic neuroendocrine neoplasms are not directly associated with the death of the person in whom they occur.

This information needs to be borne in mind when considering recent changes in incidence and prevalence. The incidence of neuroendocrine neoplasms is increasing significantly, ${ }^{28}$ and is now 3.65 per 100,000 persons. The increases over the past decade are statistically significant, but given the large quantity of undiagnosed disease, a small change in diagnostic acuity is likely to see a large proportional change in diagnostic frequency. Thus, improvements or increased use of diagnostic techniques (colonoscopy, gastroscopy, high-resolution computed tomography imaging) and increased physician awareness probably combine to cause the increased diagnosis.

The extent of undiagnosed disease is also important to consider when seeing a patient with an incidentally diagnosed tumor. A high proportion of incidentally diagnosed tumors might well not impact on survival, making initial observation a reasonable strategy in small, localized, low-grade, well differentiated lesions, especially in older patients.

Finally, the extent of undiagnosed disease and increasing incidence needs to be considered when interpreting survival in tumor registries and institutional series. Epidemiological analysis of survival has noted improvement over the last 20 years. This detection of early cases, or more importantly, cases that will not impact on survival, will cause a lead-time bias where any apparent improvement is in fact due to the relative downstaging related to earlier diagnosis.

\section{Familial syndromes and newly identified sporadic mutations demonstrate genetic alterations in overlapping pathways}

The etiology of gastroenteropancreatic neuroendocrine neoplasms is poorly understood, but this appears to be changing, particularly with advances in molecular analyses. Current examinations of the familial syndromes predisposing to gastroenteropancreatic neuroendocrine neoplasms, recently identified sporadic mutations, and epidemiological studies are all beginning to provide compelling evidence of the molecular alterations that occur in this disease.

While most cases $(>95 \%)$ are sporadic,${ }^{30}$ several familial syndromes are associated with these relatively rare tumors. These include multiple endocrine neoplasia 1, type 1 neurofibromatosis, tuberous sclerosis, von Hippel-Lindau syndrome, and others (Table 2). These syndromes are characterized by loss of function of a tumor suppressor, such as multiple endocrine neoplasia 1 (chromosome 11q13) in the syndrome of the same name, ${ }^{31}$ whose gene product, menin, is thought to interact with histone methyltransferase enzymes required for the epigenetic regulation of transcription. ${ }^{32}$ Mutations of this gene are also present in a number of sporadic cases. ${ }^{33}$ In von Hippel Lindau syndrome, the affected gene is $v H L$ (chromosome $3 \mathrm{p} 25.5)^{34}$ which has an important role in angiogenesis, and its encoded protein is involved in the degradation of hypoxia-inducible factor. ${ }^{35}$ Loss of $v H L$ results in activation of hypoxia-inducible factor and accumulation of proangiogenic growth factors. Other examples are outlined in Table 2. The gene pathways implicated in these disorders (eg, histone modification, angiogenesis) may represent pathways which are crucial for tumorigenesis in gastroenteropancreatic neuroendocrine neoplasms.

The majority of gastroenteropancreatic neuroendocrine neoplasms do not occur within a familial syndrome, and are considered sporadic. ${ }^{30}$ The location of gene mutations in a proportion (about 50\%) of these cases has been recently described, and there is some similarity with the familial syndromes. Exome sequencing of ten (nonfamilial) pancreatic neuroendocrine tumors followed by sequence analysis of 58 further pancreatic neuroendocrine neoplasms showed that the most common mutations occurred in mediators of histone organization and chromatin remodeling (multiple endocrine neoplasia $144 \%$, DAXX or ATRX 43\%) and oncogenic driver pathways such as mammalian target of rapamycin (mTOR, 15\%). ${ }^{36}$ The mTOR pathway has previously been recognized as important in studies of gene expression in pancreatic neuroendocrine tumors. ${ }^{37,38}$ Therefore, it is possible that histone organization and epigenetic changes may be a particularly fruitful area for translational research and therapeutic targeting in the future, although a challenge lies in the recognition that the gene products often have more than one role (eg, DAXX and ATRX also regulate telomeres ${ }^{39}$ ) making it more difficult to determine which function should be inhibited to prevent tumor growth. Furthermore, expression of genes involved in histone organization are not altered in poorly differentiated neuroendocrine neoplasms, ${ }^{40}$ instead typical changes include inactivating p53 and Rb mutations, ${ }^{41}$ accompanied by overexpression of $\mathrm{Bcl} 2$ (large and small cell neuroendocrine carcinomas were similar in this regard). ${ }^{40}$

Information regarding a genetic predisposition to gastroenteropancreatic neuroendocrine neoplasms from direct gene sequencing and characterization can be supplemented 
Table 2 Familial syndromes associated with gastroenteropancreatic neuroendocrine neoplasms

\begin{tabular}{|c|c|c|c|}
\hline Familial syndrome & Gene & Protein & Pattern of disease \\
\hline $\begin{array}{l}\text { Multiple endocrine } \\
\text { neoplasia type I }\end{array}$ & MEN I & $\begin{array}{l}\text { Menin: involved in histone organization } \\
\text { of gene transcription }\end{array}$ & $\begin{array}{l}\text { Hyperparathyroidism } \\
\text { Pancreatic NENs } \\
\text { Pituitary tumors }\end{array}$ \\
\hline $\begin{array}{l}\text { Multiple endocrine } \\
\text { neoplasia type } 2\end{array}$ & RET & $\begin{array}{l}\text { RET: tyrosine kinase involved in signal transduction, } \\
\text { mutation results in overactivity }\end{array}$ & $\begin{array}{l}\text { Hyperparathyroidism } \\
\text { NENs including medullary thyroid } \\
\text { cancer and pheochromocytomas }\end{array}$ \\
\hline $\begin{array}{l}\text { Neurofibromatosis } \\
\text { type I }\end{array}$ & NF-I & $\begin{array}{l}\text { Neurofibromin: Ras GTPAse activating protein, } \\
\text { regulates TSC2 and hence mTOR pathway }\end{array}$ & $\begin{array}{l}\text { Neurofibromas } \\
\text { GEP-NENs (usually duodenal) } \\
\text { Pheochromocytomas } \\
\text { Glioblastomas } \\
\text { Myeloid leukemias }\end{array}$ \\
\hline Tuberous sclerosis & $T S C-I+2$ & $\begin{array}{l}\text { Hamartin and tuberin: inhibitors of mTOR pathway, } \\
\text { loss leads to constitutional activation of mTOR }\end{array}$ & $\begin{array}{l}\text { Benign hamartomas } \\
\text { Pancreatic NENs }\end{array}$ \\
\hline $\begin{array}{l}\text { Von Hippel Lindau } \\
\text { syndrome }\end{array}$ & $v H L$ & $\begin{array}{l}\text { vHL: regulation of HIF, loss leads to accumulation } \\
\text { of angiogenic factors }\end{array}$ & $\begin{array}{l}\text { Renal cell carcinomas } \\
\text { Hemangioblastomas } \\
\text { Pancreatic NENs, } \\
\text { pheochromocytomas }\end{array}$ \\
\hline Carney complex & CNCI/PRKARIA & $\begin{array}{l}\text { Regulatory subunit of cAMP dependent } \\
\text { protein kinase } A\end{array}$ & $\begin{array}{l}\text { Testicular tumors } \\
\text { Follicular and papillary thyroid cancers }\end{array}$ \\
\hline & CNC2 & Unknown & $\begin{array}{l}\text { Cardiac myxomas } \\
\text { Adrenocortical carcinoma } \\
\text { Pancreatic NENs }\end{array}$ \\
\hline Cowden syndrome & PTEN & $\begin{array}{l}\text { PTEN: phosphatase enzyme inhibits } \\
\text { Akt signal pathway }\end{array}$ & $\begin{array}{l}\text { Benign mucocutaneous lesions } \\
\text { Breast, endometrial and renal cancers, } \\
\text { plus a variety of other cancers, including } \\
\text { pancreatic NENs }\end{array}$ \\
\hline
\end{tabular}

Note: Data from Lindor et al. ${ }^{30}$

Abbreviations: GEP, gastroenteropancreatic; NENs, neuroendocrine neoplasms; mTOR, mammalian target of rapamycin; HIF, hypoxia-inducible factor.

by examining population migration patterns that contribute to epidemiological databases. In the US Surveillance, Epidemiology and End Results registry data, small intestinal neuroendocrine neoplasms are the most common, and similar in incidence to rectal neuroendocrine neoplasms. ${ }^{28}$ Other countries with predominantly European populations show a similar pattern (eg, Norway). ${ }^{42}$ A striking finding when examining registry data from Europe compared with data from Asia is the different profile of primary tumor sites seen in each population. Asian countries have a higher proportion of rectal primaries, whereas European countries have a higher proportion of small intestinal primaries. ${ }^{29,43-47}$ Interestingly, examination of people of Asian and European descent within the US, from one to six generations after population migration, shows that these patterns persist despite the changes in diet and environment that necessarily occur in the US. Asian Americans have higher rates of rectal tumors and European Americans have higher rates of small intestinal tumors (Figure 3). This observation should be interpreted cautiously, because population level data are not ideal for etiological studies, but perhaps shows unexpected stability after migration, suggesting that a component of the predisposition to neuroendocrine neoplasms is, in part, inherent in the germ line. However, using these data, it is not possible to assess persisting culturally specific dietary and cultural practices. Neuroendocrine cells are intimately involved in sensing the luminal environment, and might be expected to be exquisitely sensitive to dietary carcinogens.

The current paradigm of malignant transformation requires cancers to accumulate several mutations/genomic hallmark events, ${ }^{48}$ but recent examples of neoplasms driven by single genetic events (eg, chronic myelogenous leukemia, gastrointestinal stromal tumors, granulosa cell tumors ${ }^{49-51}$ ) suggests that, for some tumors, particularly those with a more indolent clinical course, a single or small number of events might be sufficient to act as a key driver or malignant switch. Potentially, there is some hope that the number of genetic events facilitating neuroendocrine neoplastic transformation might be low, and therefore targetable by a realistic number of antitumor therapies. This will be discussed further in subsequent sections.

\section{Most lesions do not present with hormonal syndromes}

Patients present for four common reasons, ie, symptoms related to hormone secretion (functional), an incidental finding of a tumor on a diagnostic test (nonfunctional), symptoms 


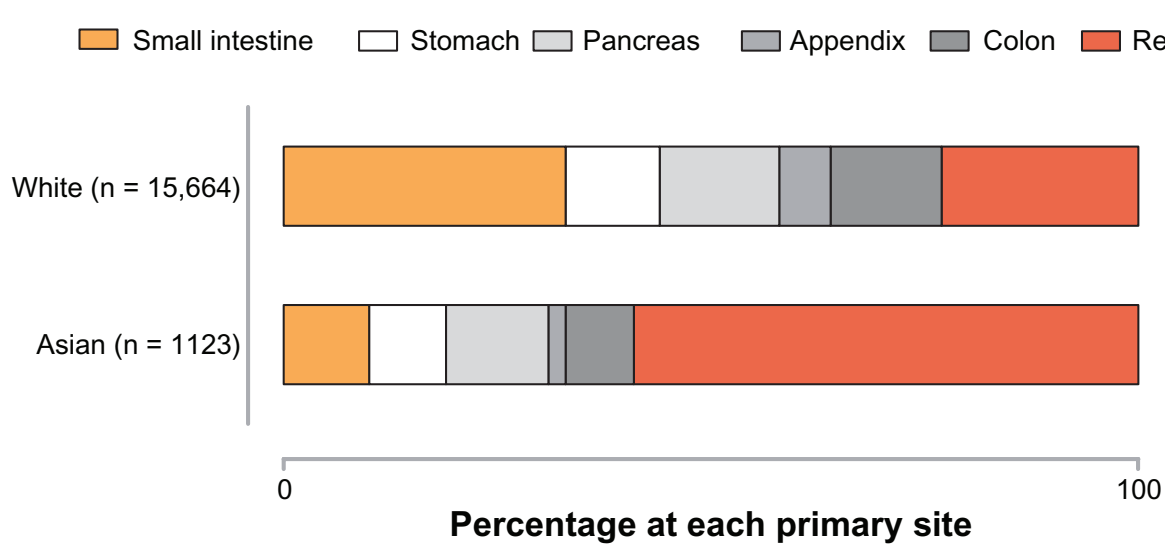

Figure 3 Differences in primary site distribution in Americans of different race and ethnicity SEER 17 2000-2008 (using SEER search terms). Notes: White Americans have a high proportion of small intestinal tumors and Asian Americans have a high proportion of rectal tumors (Modlin, unpublished data, 20I2). Abbreviation: SEER, Surveillance, Epidemiology and End Results.

of advanced malignancy that cause systemic symptoms, such as cachexia, malaise, and jaundice (nonfunctional), or cause local symptoms, such as pain or biliary obstruction (also nonfunctional).

Approximately one-third of neuroendocrine neoplasms produce functional syndromes, but this depends on the series, the site-specific expertise of the referral center, and patterns of referral. ${ }^{21,47,52}$ The most commonly recognized syndrome is the diarrhea, flushing, and bronchospasm of classic carcinoid syndrome, produced by tumors which secrete serotonin from enterochromaffin cells (eg, small intestinal neuroendocrine neoplasms). It is important to realize that small intestinal tumors often create a local desmoplastic stroma that precipitates luminal obstruction; however, these are not included in most definitions of functioning tumors, despite the obvious clinical corollary. It is also important to note that biochemically measurable secretion of a secretory product does not equate to a functioning tumor unless symptoms are present. This confusion has led to varying estimates of the incidence of carcinoid syndrome. A number of other functional syndromes are recognized (Table 3 ), including an "atypical" carcinoid syndrome due to histamine secretion by enterochromaffin-like cell tumors (gastric neuroendocrine neoplasms) which, although very rare, has a subtly different phenotype with a more pronounced urticarial rash.

There is debate over whether symptoms of hormone secretion are prognostic. Several factors would encourage a more positive survival outcome. Functional syndromes can speed recognition of the presence of tumors that might otherwise go unnoticed and cause a lead-time bias compared with tumors that continue to grow while unrecognized. The fact that the secretory machinery of the cell is still intact implies at least some elements of a well differentiated tumor and an expected positive outcome relative to poorly differentiated carcinomas. On the contrary, the presence of a carcinoid syndrome usually indicates liver metastasis as the mechanism by which secreted peptide/amines escape the portal circulation and metabolism by the liver, and thus advanced disease might suggest a poorer prognosis. Complicating this maxim is the observation that the venous drainage of rectal tumors (and even retroperitoneal metastases) can bypass the portal circulation and thus achieve a hormonal syndrome in the absence of liver metastases.

\section{Treatment strategy for poorly differentiated lesions is distinct from that in well differentiated lesions}

The treatment algorithms for poorly differentiated neuroendocrine carcinomas and well differentiated neuroendocrine tumors (NET G1 and NET G2) are currently entirely separate. Poorly differentiated neuroendocrine carcinomas have a high proliferative index and metastasize early, with a clinical course akin to small cell lung cancer. Clinical series of poorly differentiated colorectal neuroendocrine neoplasms have reported 3-year survival rates of $13 \%$ and $15 \%, 53,54$ and outcomes are similar in the foregut. ${ }^{14}$ Surgery is still the standard of care for localized lesions in most centers, but this approach is controversial because even apparently localized lesions are often already metastatic despite negative staging scans. Thus, surgical excision aimed at cure tends to be reserved for small localized lesions where excess morbidity is not expected from the procedure itself. Therapy necessarily focuses on systemic treatment. A platinum drug and etoposide, borrowed from the small cell literature, is the most common treatment approach. ${ }^{55,56}$ Many centers substitute carboplatin for cisplatin due to an improved side effect profile, although cisplatin and carboplatin have not been directly compared in 
Table 3 Functional syndromes of gastroenteropancreatic neuroendocrine neoplasms ${ }^{121-123}$

\begin{tabular}{|c|c|c|c|}
\hline Syndrome & Tumor location & Mediator & Symptoms \\
\hline Carcinoid syndrome & $\begin{array}{l}\text { Midgut } 75 \%-87 \% \\
\text { Pancreas }<1 \%\end{array}$ & $\begin{array}{l}\text { Serotonin, tachykinins, motilin, } \\
\text { prostaglandins }\end{array}$ & Flushing, diarrhea, wheeze, cardiac fibrosis \\
\hline Insulinoma & Pancreas $>99 \%$ & Insulin & Hypoglycemia, weight gain \\
\hline $\begin{array}{l}\text { Zollinger-Ellison syndrome: } \\
\text { gastrinoma }\end{array}$ & $\begin{array}{l}\text { Duodenum } 70 \% \\
\text { Pancreas 25\% } \\
\text { Others 5\% }\end{array}$ & Gastrin & Peptic ulceration, abdominal pain, diarrhea \\
\hline $\begin{array}{l}\text { Verner Morrison syndrome: } \\
\text { VIPoma }\end{array}$ & $\begin{array}{l}\text { Pancreas }>90 \% \\
\text { Other } 10 \%\end{array}$ & Vasoactive intestinal peptide & Secretory diarrhea, hypokalemia, achlorhydria \\
\hline Glucagonoma & Pancreas $100 \%$ & Glucagon & $\begin{array}{l}\text { Diabetes, weight loss, necrolytic migratory } \\
\text { erythema, diarrhea, glossitis, angular stomatitis }\end{array}$ \\
\hline Somatostatinoma (rare) & $\begin{array}{l}\text { Pancreas } 55 \% \\
\text { Small bowel } 44 \%\end{array}$ & Somatostatin & Diabetes, diarrhea, jaundice \\
\hline ACTHoma (rare) & Pancreas & Adrenocorticotrophic hormone & Cushing's syndrome \\
\hline GRFoma (rare) & $\begin{array}{l}\text { Pancreas } 30 \% \\
\text { Lung } 54 \% \\
\text { Jejunum } 7 \% \\
\text { Other } 13 \%\end{array}$ & Growth hormone releasing-hormone & Acromegaly \\
\hline PTHrPoma (rare) & Pancreas & Parathyroid hormone-related peptide & Hypercalcemia \\
\hline
\end{tabular}

Abbreviations: GEP, gastroenteropancreatic; NEN, neuroendocrine neoplasm.

gastroenteropancreatic neuroendocrine neoplasms. Response rates are high in poorly differentiated tumors, in the order of $50 \%-80 \%$, but relapse is almost always inevitable..$^{57,58}$

However, recent changes in the use of systemic therapies may lead to overlap between therapies for well and poorly differentiated gastroenteropancreatic neuroendocrine neoplasms. Temozolomide, an alkylating agent, ${ }^{59}$ and everolimus, an mTOR inhibitor, ${ }^{60}$ have been used in well differentiated pancreatic neuroendocrine neoplasms, but are now also being used in neuroendocrine carcinomas. Some centers use the combination of peptide receptor radionuclide therapy preceded by carboplatin-etoposide to address lowergrade and higher-grade tumor components, respectively, in heterogeneous metastatic gastroenteropancreatic neuroendocrine neoplasms, though the experience of this anecdotal approach has yet to be published. Furthermore, there is clinical acknowledgement of high-grade gastroenteropancreatic neuroendocrine neoplasms $(\mathrm{Ki}-67>20 \%$ ) that remain well differentiated, and it is not clear whether to treat these as well or poorly differentiated carcinomas.

\section{Therapeutic options for well differentiated tumors depend on primary site Gastric neuroendocrine neoplasms}

The primary therapy for type 1 gastric neuroendocrine neoplasms is repeated endoscopic mucosal resection. ${ }^{61}$ Tumors less than $1 \mathrm{~cm}$ may be managed with surveillance and interval resection. Tumors greater than $1 \mathrm{~cm}$ require endoscopic ultrasound to assess nodal status, with nodal involvement being an indication for surgery. Local resection and antrectomy is commonly recommended for type 1 lesions larger than $1 \mathrm{~cm}$, invasion of the muscularis propria, or positive margins following endoscopic mucosal resection. ${ }^{61}$ The aim of antrectomy is to remove the site of gastrin production, given that chronic gastrin stimulation drives the malignant change. However, there is concern that gastrin production occurs outside the antrum in the majority of patients, so the role of antrectomy is now in question. ${ }^{62}$

Type 2 lesions are also managed by endoscopic mucosal resection and surveillance, but more extensive surgery is seldom indicated unless the source of gastrin production is also localized and can be resected. Similarly, antrectomy is contraindicated in type 2 lesions because the source of gastrin is typically a gastrinoma in the duodenum or pancreas. Type 3 lesions require surgical care in the same manner as a gastric adenocarcinoma. ${ }^{63}$ Somatostatin analogs have been shown to reduce the frequency of recurrence of type 1 gastric neuroendocrine neoplasms, ${ }^{64,65}$ however, due to the typically benign nature of the disease, their use is not recommended routinely in type 1 or 2 tumors unless a functional syndrome is present. ${ }^{63}$ There is also some evidence that stopping this medication may be followed by a more aggressive relapse and so somatostatin analog therapy is not recommended at this time. ${ }^{66}$

\section{Pancreatic neuroendocrine neoplasms}

The treatment of pancreatic gastroenteropancreatic neuroendocrine neoplasms is complicated, and multidisciplinary 
input is essential. Localized tumors should be removed by surgery where feasible. ${ }^{67}$ In the absence of metastases outside the liver, resection of unilobar hepatic metastases in a specialist center should be considered, and two-step resection or combination with radiofrequency ablation considered in complex metastatic involvement. ${ }^{68}$ Pancreatic lesions with predominantly liver metastases not amenable to surgery can also undergo locally directed therapy such as selective internal radiotherapy, cryotherapy, radiofrequency ablation, and hepatic artery embolization with or without a chemotherapeutic agent. Although experience with these approaches is limited, palliation appears feasible. ${ }^{69}$ All have shown radiological and symptomatic improvement, and are usually used for nonoperative situations or when a single large lesion is the cause of significant symptoms not controlled by other therapy.

Metastatic disease can be treated with somatostatin analogs or interferon to achieve symptomatic improvement in functioning tumors, but there is limited evidence of disease control with a pancreatic primary. ${ }^{69-71}$ Somatostatin analogs are better tolerated than interferon, and combining the drugs can achieve more effective control of carcinoid syndrome. ${ }^{72}$ Trials of somatostatin analogs have included a mixture of gastroenteropancreatic neuroendocrine neoplasm sites, have not included a placebo comparison, and have often not required proof of progressive disease prior to treatment. The results of these studies must therefore be interpreted with caution. ${ }^{69}$

Metastatic pancreatic neuroendocrine neoplasms are more responsive to traditional cytotoxic chemotherapy than other neuroendocrine neoplasms and can benefit from streptozotocin with 5-fluorouracil with or without doxorubicin. ${ }^{73,74}$ Response rates to cytotoxic chemotherapy have been approximately $30 \%-40 \%$, although some studies have included nonradiological criteria for response and also included some higher-grade lesions, possibly overestimating the benefit of these treatments. Early clinical trials with other 5-fluorouracil-based combinations, both in pretreated and treatment-naïve patients, have used oxaliplatin, ${ }^{75}$ irinotecan, ${ }^{76}$ and temozolomide, ${ }^{77}$ and achieved responses in $30 \%, 5 \%$, and $70 \%$, respectively.

More recently, targeted agents including everolimus, ${ }^{7}$ acting through the mTOR pathway and sunitinib, ${ }^{6}$ a vascular endothelial growth inhibitor (among other targets), have been tested. Response rates to both therapies are very low $(<9 \%)$ and the improvements in progression-free survival in both cases is from 5 months for untreated patients to 11 months with treatment, suggesting only modest benefit.
Future research will look at how these agents can be combined, as well as with alternative treatment modalities. For example, combining temsirolimus, an mTOR inhibitor, and bevacizumab, a vascular endothelial growth inhibitor, has recently been demonstrated to be effective in an interim analysis of a Phase II trial, with a response rate of $52 \%$ by Response Evaluation Criteria In Solid Tumors (RECIST) criteria $(\mathrm{n}=25) .^{78}$

An additional consideration for the clinician is the choice of endpoints in the Phase III trials of everolimus and sunitinib. These targeted therapies were trialed with the primary endpoint of progression-free survival which has been criticized, although it is probably not feasible to run a randomized clinical trial with overall survival as an endpoint in these slow-growing tumors. Statistical modeling ${ }^{79}$ suggests that the sample size of approximately 2500 patients would be needed to power a study that could detect a significant difference in overall survival using these therapies. Since it has been estimated that only approximately 5000 Americans have a pancreatic net, it is difficult to conceive how this trial could be run. Thus, for the foreseeable future, progressionfree survival appears to be the endpoint that we must cautiously accept or tolerate. As an additional consideration, the current emphasis on RECIST criteria may be inadequate to capture clinically meaningful responses to treatment, and to assess potentially cytostatic rather than cytotoxic therapy. Alternatives, such as the Choi criteria, have been developed in soft tissue sarcomas and are beginning to be evaluated in gastroenteropancreatic neuroendocrine neoplasms ${ }^{80,81}$ (NCT01525550).

Systemic treatment of advanced gastroenteropancreatic neuroendocrine neoplasms, irrespective of primary site, can also be undertaken with peptide receptor radionuclide therapy. Although used increasingly, there has been relatively little Phase II trial reporting to support this, and importantly peptide receptor radionuclide therapy is yet to be tested against other therapies in a randomized controlled trial. Phase II trials show response rates in the order of $30 \%$, with the peak effect being seen somewhere between 3 and 9 months after therapy. ${ }^{8,82}$ The safety of combining peptide receptor radionuclide therapy with the radiosensitizing agent 5-fluorouracil (or capecitabine) has been demonstrated and may achieve additional responses. ${ }^{83,84}$ An indirect predictive biomarker for peptide receptor radionuclide therapy is a high level of tracer uptake on radiolabeled octreotide scintigraphy or positron emission tomography. Further attempts to improve on peptide receptor radionuclide therapy will include using combinations 
of radionuclides, ${ }^{85,86}$ novel radionuclides (eg, bismuth), and tailored dosimetry. ${ }^{87}$

\section{Small intestinal neuroendocrine neoplasms}

The most significant recent advance is the recognition that cytotoxic chemotherapy, with response rates of zero to $15 \%,{ }^{88}$ has no role in well differentiated small intestinal neuroendocrine neoplasms. ${ }^{89}$ Therefore, therapy in advanced disease should currently focus on surgical debulking, with a current preference for removal of the primary lesion due to the likelihood that the first symptoms will be from bowel obstruction and resection is better undertaken in the elective setting. Curative tumor resection is possible in up to $20 \%$ of patients with metastatic disease only in the liver, ${ }^{90}$ although whether this correlates with improved survival is unclear and has not been tested in a prospective study. The treatment of liver metastases is the same as described in the previous section concerning pancreatic neuroendocrine neoplasms. There is also a role for peptide receptor radionuclide therapy in metastatic neuroendocrine neoplasms in the small intestine, ${ }^{91}$ although as in other primary sites, prospective evaluation is awaited.

Somatostatin analogs are indicated for symptom control in functioning gastroenteropancreatic neuroendocrine neoplasms and may confer survival benefit. The PROMID study ${ }^{5}$ has shown an improvement in progression-free survival extending to some patients with advanced midgut neuroendocrine neoplasms. This fits with anecdotal experience and with preclinical data suggesting an antitumor effect of somatostatin analogs..$^{92}$ However, the study was small $(\mathrm{n}=85)$, took a long time to recruit ( 8 years), and there were some differences between the groups that might have favored the octreotide arm. ${ }^{93}$ There is currently debate about how the results of this trial should influence practice. Pasireotide is a somatostatin analog with a broader range of activity at somatostatin receptors than octreotide and has been shown to achieve symptom control in some patients with octreotide-resistant functional syndromes in early phase research ${ }^{94}$ as well as inhibit neuroendocrine cell lines in vitro. ${ }^{95}$ This agent is currently in clinical trials comparing it with octreotide (NCT00690430) and in combination with everolimus (NCT00804336), although a recent trial in pituitary tumors raised concern regarding iatrogenic hyperglycemia. ${ }^{96}$

Molecular targeted therapies again offer an alternative approach, but have been less promising in small intestinal neuroendocrine neoplasms than in pancreatic neuroendocrine neoplasms. Bevacizumab has shown modest clinical activity, ${ }^{97}$ while the antivascular endothelial growth tyrosine kinase inhibitors, sunitinib, sorafenib, and valatanib, have shown almost no responses. ${ }^{98-100}$ Similarly, targeting epidermal growth factor with gefitinib has been ineffective. ${ }^{101}$ Mixed results were documented after targeting the mTOR pathway. Temsirolimus has produced disappointing results, with a response rate of $<5 \%$ and with excessive toxicity. ${ }^{102}$ Conversely, everolimus showed more clinical activity in early phase trials, ${ }^{97,103}$ but the recent Phase III RADIANT2 trial did not achieve statistically significant improvement in progression-free survival in patients with carcinoid syndrome, ${ }^{104}$ and is to be repeated in patients with "non-functioning" tumors.

\section{Appendiceal neuroendocrine neoplasms}

The treatment of appendiceal neuroendocrine neoplasms is based on clinical series which have suggested that the size of the primary $(>1 \mathrm{~cm})$ and invasion of the mesoappendix (by $>0.3 \mathrm{~cm}$ ) are important prognostic variables. ${ }^{105}$ Interpretation is made difficult by the often incidental discovery of these tumors at the time of appendectomy for acute appendicitis. However, a small proportion of these lesions do metastasize (about $10 \%$ of tumors $1-2 \mathrm{~cm}$, about $40 \%$ of tumors $>2 \mathrm{~cm}$ ) and right hemicolectomy should be considered for tumors with risk factors $(>1 \mathrm{~cm}$, mesoappendix invasion $>3 \mathrm{~mm}$, location in base, angioinvasion). They tend not to be associated with symptoms of hormone secretion. ${ }^{106}$

\section{Rectal neuroendocrine neoplasms}

For the most part, rectal neuroendocrine neoplasms are small solitary lesions that can be removed endoscopically and do not require further treatment. However, in about $2 \%$ of cases, these lesions are metastatic and have a poor prognosis. Surgical resection as for rectal adenocarcinoma should therefore be undertaken for lesions $>2 \mathrm{~cm}$ or smaller lesions with muscularis invasion or regional metastases. ${ }^{107}$ The primary should be resected in the presence of metastatic disease if there is potential for causing obstruction. Otherwise, metastatic rectal neuroendocrine neoplasms should be managed much as pancreatic lesions, although there is no evidence for this approach. ${ }^{107}$

The complexity of managing gastroenteropancreatic neuroendocrine neoplasms is reflected in the published trials, which are difficult to interpret due to heterogenous trial populations and differing outcome measures. The results of trials of systemic therapy for gastroenteropancreatic 


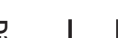
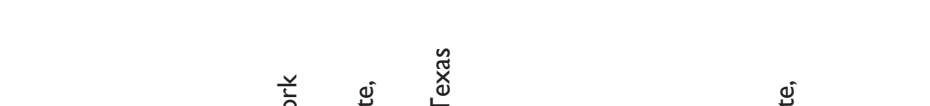


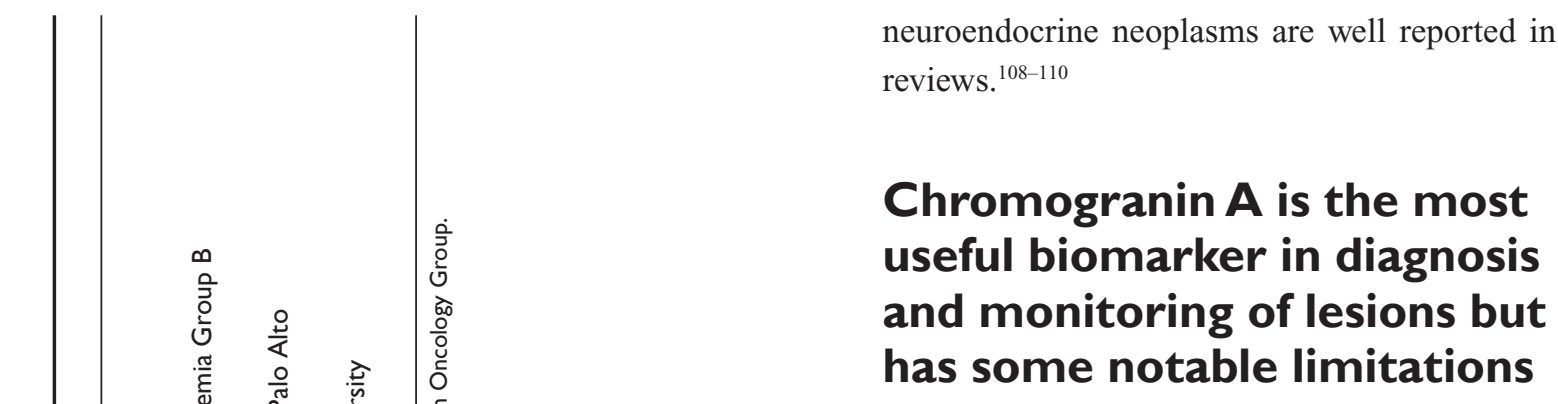

The secretory capability of gastroenteropancreatic neuroendocrine neoplasms lends itself to the use of biochemical markers in diagnosis and monitoring of response, and early responses to chromogranin A after treatment may correlate with progression-free survival. ${ }^{111}$ Potential biomarkers include chromogranin A, 5-hydroxyindoleacetic acid, and neuronspecific enolase. Chromogranin A, a glycoprotein stored in secretory vesicles, is almost ubiquitous in well differentiated and secretory neuroendocrine tumor cells, although is not always so easily detected in plasma. ${ }^{12}$ Chromogranin A is useful in both functioning and nonfunctioning neuroendocrine neoplasms and is more sensitive than other biochemical markers. ${ }^{13,114}$ However, there are many caveats when using chromogranin A. Chromogranin A becomes elevated after eating, and even exercise and anxiety can cause false positive results. Chromogranin A levels are elevated in hepatic and renal dysfunction, as well as in atrophic gastritis and chronic proton pump inhibition (which predispose to enterchromaffinlike cell hyperplasia). Several cardiovascular (eg, hypertension, heart failure), endocrine (eg, hyperthyroidism), and gastrointestinal disorders (eg, inflammatory bowel disease, liver cirrhosis) also cause chromogranin A elevation. Further, non-neuroendocrine cancers have been associated with increases in chromogranin A, including cancers of the breast, pancreas, colon, ovary, and prostate, and thus chromogranin A should not be used as a diagnostic tool. ${ }^{115}$

5-Hydroxyindoleacetic acid, the end product of serotonin metabolism, and most reliably measured in the urine over 24 hours, and neuron-specific enolase are both highly specific, approaching $100 \%$ for some functioning neuroendocrine neoplasms. However, they lack sensitivity; in one study of mixed neuroendocrine neoplasms, 5-hydroxyindoleacetic acid and neuron-specific enolase showed a sensitivity of $33 \%$ and $35 \%$, respectively, compared with $68 \%$ for chromogranin A. ${ }^{114}$ The sensitivity of 5-hydroxyindoleacetic acid is highest (up to 73\%) in midgut carcinoids (mostly small intestinal neuroendocrine neoplasms) especially in the presence of carcinoid syndrome. ${ }^{116}$ 5-Hydroxyindoleacetic acid false-positives can occur with tryptophan-containing foods and some medicines. ${ }^{117}$ Neuron-specific enolase may 
be useful in poorly differentiated neuroendocrine carcinomas where other markers are often negative ${ }^{56}$ Chromogranin A and 5-hydroxyindoleacetic acid also have prognostic value, with higher levels associated with a poor outcome. ${ }^{118}$

\section{Treatment should only be considered by clinicians in a multidisciplinary team}

The treatment of gastroenteropancreatic neuroendocrine neoplasms is predominantly not evidence-based, and is shaped more by the local skill set and funding restrictions than by clear scientific recommendations. This makes treatment decisions particularly difficult for clinicians and impossible for clinicians acting alone. The number of treatment modalities now available is growing and the potential permutations and combinations of surgery, systemic therapy, nuclear medicine, and liver-directed therapies is enormous, and the ideal combination remains a crucial question for each patient.

\section{All patients should consider participating in a clinical trial, since treatment strategies have not been directly compared, leading to large interpractice variability}

The current state of knowledge regarding the management of gastroenteropancreatic neuroendocrine neoplasms leads to a final inescapable conclusion. A coordinated international clinical trials program is essential. ${ }^{119}$ Further, there is a genuine possibility that gastroenteropancreatic neuroendocrine neoplasms will be more suitable to molecular targeted therapies than many other malignancies, making this an optimistic time for patients with these heterogeneous tumors. Many trials are currently recruiting (Table 4) and the authors would strongly encourage the reader to refer patients for trial participation.

\section{Conclusion}

The clinician considering a new diagnosis of gastroenteropancreatic neuroendocrine neoplasm could be well served by considering the following etiological and epidemiological principles:

- Classification systems are becoming increasingly confluent across transnational (World Health Organization), European (European Neuroendocrine Tumor Society) and US American Joint Committee on Cancer) systems, and more similar to other cancers in the use of grading, differentiation, and staging.
- There is a progression from hyperplasia to dysplasia to neoplasia in some gastroenteropancreatic neuroendocrine neoplasms of the foregut, but this transition has not yet been observed at more distal sites.

- The majority of gastroenteropancreatic neuroendocrine neoplasms are never diagnosed and do not contribute to mortality. Therefore, a high proportion of lesions discovered incidentally will not impact on mortality, and so initial or long-term observation may be warranted.

- The genetic cause of gastroenteropancreatic neuroendocrine neoplasms is beginning to be uncovered, and relevant pathways that might facilitate therapeutic inhibition have started to be identified.

- Most gastroenteropancreatic neuroendocrine neoplasms do not present with hormonal syndromes, eg, carcinoid syndrome, despite this being the best known symptom in this group of tumors.

- Treatment strategies for poorly differentiated gastroenteropancreatic neuroendocrine neoplasms are divergent from those of well differentiated gastroenteropancreatic neuroendocrine neoplasms. The cornerstone of therapy for well differentiated gastroenteropancreatic neuroendocrine neoplasms is surgery, but is chemotherapy for poorly differentiated gastroenteropancreatic neuroendocrine neoplasms.

- The therapeutic options for well differentiated gastroenteropancreatic neuroendocrine neoplasms depend on the primary site of the lesion. Resection of the primary is recommended in metastatic luminal neuroendocrine neoplasms because obstruction is often the initial complication.

- Chromogranin A is a modestly effective biomarker that is more useful in well differentiated tumors. The clinical should note limitations of both sensitivity and specificity.

- Treatment should only be considered by clinicians who consider themselves part of a multidisciplinary team. There are too many options to be assessed by a single clinician.

- Clinical trials are essential, and international collaboration will be required to obtain the necessary sample sizes. Treatment strategies for well differentiated gastroenteropancreatic neuroendocrine neoplasms are protean and have not been compared with each other. There is no head-to-head comparison of therapies in gastroenteropancreatic neuroendocrine neoplasms, and recommendations are mostly based on expert opinion rather than clinical trials. 


\section{Disclosure}

The authors report no conflicts of interest in this work.

\section{References}

1. Modlin IM, Oberg K, Chung DC, et al. Gastroenteropancreatic neuroendocrine tumours. Lancet Oncol. 2008;9(1):61-72.

2. Rindi G, Klimstra DS, Arnold R, et al. Nomenclature and classification of neuroendocrine neoplasms of the digestive system. In: Bosman FT, Carneiro F, Hruban RH, Theise ND, editors. WHO Classification of the Digestive System. 4th ed. Lyon, France: International Agency for Research on Cancer; 2010.

3. Gustafsson BI, Bakke I, Tommeras K, Waldum HL. A new method for visualization of gut mucosal cells, describing the enterochromaffin cell in the rat gastrointestinal tract. Scand J Gastroenterol. 2006;41(4):390-395.

4. Solcia E. Histological Typing of Endocrine Tumors. World Health Organization International Histological Classification of Tumors. 2nd ed. Berlin, Germany: Springer; 2000.

5. Rinke A, Muller HH, Schade-Brittinger C, et al. Placebo-controlled, double-blind, prospective, randomized study on the effect of octreotide LAR in the control of tumor growth in patients with metastatic neuroendocrine midgut tumors: a report from the PROMID Study Group. J Clin Oncol. 2009;27(28):4656-4663.

6. Raymond E, Dahan L, Raoul JL, et al. Sunitinib malate for the treatment of pancreatic neuroendocrine tumors. $N$ Engl J Med. 2011;364(6):501-513.

7. Yao JC, Shah MH, Ito T, et al. Everolimus for advanced pancreatic neuroendocrine tumors. $N$ Engl J Med. 2011;364(6):514-523.

8. Kwekkeboom DJ, Teunissen JJ, Bakker WH, et al. Radiolabeled somatostatin analog [177Lu-DOTA0,Tyr3]octreotate in patients with endocrine gastroenteropancreatic tumors. J Clin Oncol. 2005;23(12): 2754-2762.

9. Schonhoff SE, Giel-Moloney M, Leiter AB. Minireview: development and differentiation of gut endocrine cells. Endocrinology. 2004;145(6): 2639-2644.

10. Power DG, Shia J, Allen PJ, Jarnagin WR, O'Reilly EM. Synchronous epithelial and neuroendocrine cancers of the pancreas: case series of a rare occurrence. Clin Colorectal Cancer. 2011;10(2):146-150.

11. Oberndorfer S. Karzinoide Tumoren des Dünndarms. [Carcinoid tumors of the small intestine]. Frankf Z Pathol. 1907;1:426-432. Germany.

12. Williams ED, Sandler M. The classification of carcinoid tumours. Lancet. 1963;1(7275):238-239.

13. Solcia E. Histological typing of endocrine tumors. World Health Organization International Histological Classification of Tumors. 2nd ed. Berlin, Germany: Springer; 2000.

14. Rindi G, Bordi C, Rappel S, La Rosa S, Stolte M, Solcia E. Gastric carcinoids and neuroendocrine carcinomas: pathogenesis, pathology, and behavior. World J Surg. 1996;20(2):168-172.

15. Plockinger U, Rindi G, Arnold R, et al. Guidelines for the diagnosis and treatment of neuroendocrine gastrointestinal tumours. A consensus statement on behalf of the European Neuroendocrine Tumour Society (ENETS). Neuroendocrinology. 2004;80(6):394-424

16. Rindi G, Kloppel G, Alhman H, et al. TNM staging of foregut (neuro) endocrine tumors: a consensus proposal including a grading system. Virchows Arch. 2006;449(4):395-401.

17. Klimstra DS, Modlin IR, Coppola D, Lloyd RV, Suster S. The pathologic classification of neuroendocrine tumors: a review of nomenclature, grading, and staging systems. Pancreas. 2010;39(6): 707-712.

18. Rindi G, Kloppel G, Couvelard A, et al. TNM staging of midgut and hindgut (neuro) endocrine tumors: a consensus proposal including a grading system. Virchows Arch. 2007;451(4):757-762.

19. Jann H, Roll S, Couvelard A, et al. Neuroendocrine tumors of midgut and hindgut origin: tumor-node-metastasis classification determines clinical outcome. Cancer. 2011;117(15):3332-3341.
20. Strosberg JR, Cheema A, Weber J, Han G, Coppola D, Kvols LK. Prognostic validity of a novel American Joint Committee on Cancer Staging Classification for pancreatic neuroendocrine tumors. J Clin Oncol. 2011;29(22):3044-3049.

21. Panzuto F, Nasoni S, Falconi M, et al. Prognostic factors and survival in endocrine tumor patients: comparison between gastrointestinal and pancreatic localization. Endocr Relat Cancer. 2005;12(4):1083-1092.

22. Rindi G, Solcia E. Endocrine hyperplasia and dysplasia in the pathogenesis of gastrointestinal and pancreatic endocrine tumors. Gastroenterol Clin North Am. 2007;36(4):851-865, vi.

23. Rindi G, Inzani F, Solcia E. Pathology of gastrointestinal disorders. Endocrinol Metab Clin North Am. 2010;39(4):713-727.

24. Bordi C, Yu JY, Baggi MT, et al. Gastric carcinoids and their precursor lesions. A histologic and immunohistochemical study of 23 cases. Cancer. 1991;67(3):663-672.

25. Lawrence B, Kidd M, Svejda B, Modlin I. A clinical perspective on gastric neuroendocrine neoplasia. Curr Gastroenterol Rep. 2011;13(1): 101-109.

26. Berge T, Linell F. Carcinoid tumours. Frequency in a defined population during a 12-year period. Acta Pathol Microbiol Scand A. 1976;84(4):322-330.

27. Lam KY, Lo CY. Pancreatic endocrine tumour: a 22-year clinicopathological experience with morphological, immunohistochemical observation and a review of the literature. Eur J Surg Oncol. 1997;23(1):36-42.

28. Lawrence B, Gustafsson BI, Chan A, Svejda B, Kidd M, Modlin IM. The epidemiology of gastroenteropancreatic neuroendocrine tumors. Endocrinol Metab Clin North Am. 2011;40(1):1-18, vii.

29. Yao JC, Hassan M, Phan A, et al. One hundred years after "carcinoid": epidemiology of and prognostic factors for neuroendocrine tumors in 35,825 cases in the United States. J Clin Oncol. 2008;26(18): 3063-3072.

30. Lindor NM, McMaster ML, Lindor CJ, Greene MH. Concise handbook of familial cancer susceptibility syndromes - second edition. $J$ Natl Cancer Inst Monogr. 2008;38:1-93.

31. Larsson C, Skogseid B, Oberg K, Nakamura Y, Nordenskjold M. Multiple endocrine neoplasia type 1 gene maps to chromosome 11 and is lost in insulinoma. Nature. 1988;332(6159):85-87.

32. Marx SJ, Agarwal SK, Kester MB, et al. Germline and somatic mutation of the gene for multiple endocrine neoplasia type 1 (MEN1). J Intern Med. 1998;243(6):447-453.

33. Fujii T, Kawai T, Saito K, et al. MEN1 gene mutations in sporadic neuroendocrine tumors of foregut derivation. Pathol Int. 1999;49(11): 968-973.

34. Latif F, Tory K, Gnarra J, et al. Identification of the von Hippel-Lindau disease tumor suppressor gene. Science. 1993;260(5112):1317-1320.

35. Maxwell PH, Wiesener MS, Chang GW, et al. The tumour suppressor protein VHL targets hypoxia-inducible factors for oxygen-dependent proteolysis. Nature. 1999;399(6733):271-275.

36. Jiao Y, Shi C, Edil BH, et al. DAXX/ATRX, MEN1, and mTOR pathway genes are frequently altered in pancreatic neuroendocrine tumors. Science. 2011;331(6021):1199-1203.

37. Missiaglia E, Dalai I, Barbi S, et al. Pancreatic endocrine tumors: expression profiling evidences a role for AKT-mTOR pathway. J Clin Oncol. 2010;28(2):245-255.

38. Zhou CF, Ji J, Yuan F, et al. mTOR activation in well differentiated pancreatic neuroendocrine tumors: a retrospective study on 34 cases. Hepatogastroenterology. 2011;58(112):2140-2143.

39. Heaphy CM, de Wilde RF, Jiao Y, et al. Altered telomeres in tumors with ATRX and DAXX mutations. Science. 2011;333(6041):425.

40. Yachida S, Vakiani E, White CM, et al. Small cell and large cell neuroendocrine carcinomas of the pancreas are genetically similar and distinct from well-differentiated pancreatic neuroendocrine tumors. Am J Surg Pathol. 2012;36(2):173-184.

41. Hu W, Feng Z, Modica I, et al. Gene amplifications in well-differentiated pancreatic neuroendocrine tumors inactivate the p53 pathway. Genes Cancer. 2010;1(4):360-368. 
42. Hauso O, Gustafsson BI, Kidd M, et al. Neuroendocrine tumor epidemiology: contrasting Norway and North America. Cancer. 2008;113(10):2655-2664.

43. Qubaiah O, Devesa SS, Platz CE, Huycke MM, Dores GM. Small intestinal cancer: a population-based study of incidence and survival patterns in the United States, 1992 to 2006. Cancer Epidemiol Biomarkers Prev. 2010;19(8):1908-1918.

44. Garcia-Carbonero R, Capdevila J, Crespo-Herrero G, et al. Incidence, patterns of care and prognostic factors for outcome of gastroenteropancreatic neuroendocrine tumors (GEP-NETs): results from the National Cancer Registry of Spain (RGETNE). Ann Oncol. 2010;21(9):1794-1803.

45. Modlin IM, Lye KD, Kidd M. A 5-decade analysis of 13,715 carcinoid tumors. Cancer. 2003;97(4):934-959.

46. Niederle MB, Hackl M, Kaserer K, Niederle B. Gastroenteropancreatic neuroendocrine tumours: the current incidence and staging based on the WHO and European Neuroendocrine Tumour Society classification: an analysis based on prospectively collected parameters. Endocr Relat Cancer. 2010;17(4):909-918.

47. Pape UF, Berndt U, Muller-Nordhorn J, et al. Prognostic factors of long-term outcome in gastroenteropancreatic neuroendocrine tumours. Endocr Relat Cancer. 2008;15(4):1083-1097.

48. Hanahan D, Weinberg RA. The hallmarks of cancer. Cell. 2000;100(1): 57-70.

49. Kurzrock R, Gutterman JU, Talpaz M. The molecular genetics of Philadelphia chromosome-positive leukemias. $N$ Engl J Med. 1988; 319(15):990-998.

50. Miettinen M, Lasota J. Gastrointestinal stromal tumors: review on morphology, molecular pathology, prognosis, and differential diagnosis Arch Pathol Lab Med. 2006;130(10):1466-1478.

51. Jamieson S, Fuller PJ. Molecular pathogenesis of granulosa cell tumors of the ovary. Endocr Rev. 2012;33(1):109-144.

52. Kirshbom PM, Kherani AR, Onaitis MW, Feldman JM, Tyler DS Carcinoids of unknown origin: comparative analysis with foregut, midgut, and hindgut carcinoids. Surgery. 1998;124(6):1063-1070.

53. Saclarides TJ, Szeluga D, Staren ED. Neuroendocrine cancers of the colon and rectum. Results of a ten-year experience. Dis Colon Rectum. 1994;37(7):635-642.

54. Bernick PE, Klimstra DS, Shia J, et al. Neuroendocrine carcinomas of the colon and rectum. Dis Colon Rectum. 2004;47(2):163-169.

55. Ahlman H, Nilsson O, McNicol AM, et al. Poorly-differentiated endocrine carcinomas of midgut and hindgut origin. Neuroendocrinology. 2008;87(1):40-46.

56. Nilsson O, Van Cutsem E, Delle Fave G, et al. Poorly differentiated carcinomas of the foregut (gastric, duodenal and pancreatic). Neuroendocrinology. 2006;84(3):212-215.

57. Olsen IH, Langer SW, Jepsen I, et al. First-line treatment of patients with disseminated poorly differentiated neuroendocrine carcinomas with carboplatin, etoposide, and vincristine: a single institution experience. Acta Oncol. 2012;51(1):97-100.

58. Strosberg JR, Coppola D, Klimstra DS, et al. The NANETS consensus guidelines for the diagnosis and management of poorly differentiated (high-grade) extrapulmonary neuroendocrine carcinomas. Pancreas. 2010;39(6):799-800.

59. Lindholm DP, Eriksson B, Granberg D. Response to temozolomide and bevacizumab in a patient with poorly differentiated neuroendocrine carcinoma. Med Oncol. 2012;29(1):301-303.

60. Catena L, Bajetta E, Milione M, et al. Mammalian target of rapamycin expression in poorly differentiated endocrine carcinoma: clinical and therapeutic future challenges. Target Oncol. 2011;6(2): 65-68.

61. Delle Fave G, Kwekkeboom DJ, Van Cutsem E, et al. ENETS consensus guidelines for the management of patients with gastroduodenal neoplasms. Neuroendocrinology. 2012;95(2):74-87.

62. Ozao-Choy J, Buch K, Strauchen JA, Warner RR, Divino CM. Laparoscopic antrectomy for the treatment of type I gastric carcinoid tumors. J Surg Res. 2010;162(1):22-25.
63. Ruszniewski P, Delle Fave G, Cadiot G, et al. Well-differentiated gastric tumors/carcinomas. Neuroendocrinology. 2006;84(3):158-164.

64. Modlin IM, Kumar R, Nangia A, Soroka CJ, Pasikhov D, Goldenring JR. Gastrin-dependent inhibitory effects of octreotide on the genesis of gastric ECLomas. Surgery. 1992;112(6):1048-1056.

65. Tomassetti P, Migliori M, Caletti GC, Fusaroli P, Corinaldesi R, Gullo L. Treatment of type II gastric carcinoid tumors with somatostatin analogues. $N$ Engl J Med. 2000;343(8):551-554.

66. Jianu CS, Fossmark R, Syversen U, Hauso O, Fykse V, Waldum HL. Five-year follow-up of patients treated for 1 year with octreotide long-acting release for enterochromaffin-like cell carcinoids. Scand J Gastroenterol. 2011;46(4):456-463.

67. Falconi M, Bartsch DK, Eriksson B, et al. ENETS consensus guidelines for the management of patients with digestive neuroendocrine neoplasms of the digestive system: well-differentiated pancreatic non-functioning tumors. Neuroendocrinology. 2012;95(2): 120-134.

68. Pavel M, Baudin E, Couvelard A, et al. ENETS consensus guidelines for the management of patients with liver and other distant metastases from neuroendocrine neoplasms of foregut, midgut, hindgut, and unknown primary. Neuroendocrinology. 2012;95(2):157-176.

69. Falconi M, Plockinger U, Kwekkeboom DJ, et al. Well-differentiated pancreatic nonfunctioning tumors/carcinoma. Neuroendocrinology. 2006;84(3):196-211.

70. Panzuto F, Di Fonzo M, Iannicelli E, et al. Long-term clinical outcome of somatostatin analogues for treatment of progressive, metastatic, well-differentiated entero-pancreatic endocrine carcinoma. Ann Oncol. 2006;17(3):461-466.

71. Aparicio T, Ducreux M, Baudin E, et al. Antitumour activity of somatostatin analogues in progressive metastatic neuroendocrine tumours. Eur J Cancer. 2001;37(8):1014-1019.

72. Faiss S, Pape UF, Bohmig M, et al. Prospective, randomized, multicenter trial on the antiproliferative effect of lanreotide, interferon alfa, and their combination for therapy of metastatic neuroendocrine gastroenteropancreatic tumors - the International Lanreotide and Interferon Alfa Study Group. J Clin Oncol. 2003;21(14):2689-2696.

73. Moertel CG, Lefkopoulo M, Lipsitz S, Hahn RG, Klaassen D. Streptozocin-doxorubicin, streptozocin-fluorouracil or chlorozotocin in the treatment of advanced islet-cell carcinoma. $N$ Engl J Med. 1992;326(8): 519-523.

74. Kouvaraki MA, Ajani JA, Hoff P, et al. Fluorouracil, doxorubicin, and streptozocin in the treatment of patients with locally advanced and metastatic pancreatic endocrine carcinomas. J Clin Oncol. 2004; 22(23):4762-4771.

75. Bajetta E, Catena L, Procopio G, et al. Are capecitabine and oxaliplatin (XELOX) suitable treatments for progressing low-grade and high-grade neuroendocrine tumours? Cancer Chemother Pharmacol. 2007;59(5):637-642.

76. Ducreux MP, Boige V, Leboulleux S, et al. A phase II study of irinotecan with 5-fluorouracil and leucovorin in patients with pretreated gastroenteropancreatic well-differentiated endocrine carcinomas. Oncology. 2006;70(2):134-140.

77. Strosberg JR, Fine RL, Choi J, et al. First-line chemotherapy with capecitabine and temozolomide in patients with metastatic pancreatic endocrine carcinomas. Cancer. 2011;117(2):268-275.

78. Hobday TJ, Qin R, Reidy DL, et al. Multicenter Phase II trial of temsirolimus and bevacizumab in pancreatic neuroendocrine tumors: results of a planned interim efficacy analysis. Paper presented at the American Society of Clinical Oncology Gastrointestinal Symposium, January 19-21, 2012, San Francisco, CA.

79. Broglio KR, Berry DA. Detecting an overall survival benefit that is derived from progression-free survival. J Natl Cancer Inst. 2009; 101(23):1642-1649.

80. Grande E, Jose Diez J, Pachon V, et al. Response by Choi criteria to sunitinib plus octreotide LAR in a functional heavily pretreated advanced pancreatic neuroendocrine tumor. Anticancer Drugs. 2011;22(5):477-479. 
81. Faivre S, Ronot M, Dreyer C, et al. Imaging response in neuroendocrine tumors treated with targeted therapies: the experience of sunitinib. Target Oncol. 2012;7(2):127-133.

82. Kwekkeboom DJ, Mueller-Brand J, Paganelli G, et al. Overview of results of peptide receptor radionuclide therapy with 3 radiolabeled somatostatin analogs. J Nucl Med. 2005;46 Suppl 1:62S-66S.

83. van Essen M, Krenning EP, Kam BL, de Herder WW, van Aken MO, Kwekkeboom DJ. Report on short-term side effects of treatments with 177Lu-octreotate in combination with capecitabine in seven patients with gastroenteropancreatic neuroendocrine tumours. Eur J Nucl Med Mol Imaging. 2008;35(4):743-748.

84. Kong G, Johnston V, Ramdave S, Lau E, Rischin D, Hicks RJ. High-administered activity In-111 octreotide therapy with concomitant radiosensitizing 5FU chemotherapy for treatment of neuroendocrine tumors: preliminary experience. Cancer Biother Radiopharm. 2009;24(5):527-533.

85. De Jong M, Valkema R, Jamar F, et al. Somatostatin receptor-targeted radionuclide therapy of tumors: preclinical and clinical findings. Semin Nucl Med. 2002;32(2):133-140.

86. Villard L, Romer A, Marincek N, et al. Cohort study of somatostatinbased radiopeptide therapy with [90Y-DOTA]-TOC versus [90YDOTA]-TOC plus [177Lu-DOTA]-TOC in neuroendocrine cancers. J Clin Oncol. 2012;30(10):1100-1106.

87. Forrer F, Krenning EP, Kooij PP, et al. Bone marrow dosimetry in peptide receptor radionuclide therapy with [177Lu-DOTA(0), Tyr(3)] octreotate. Eur J Nucl Med Mol Imaging. 2009;36(7):1138-1146.

88. Sun W, Lipsitz S, Catalano P, Mailliard JA, Haller DG; Eastern Cooperative Oncology G. Phase II/III study of doxorubicin with fluorouracil compared with streptozocin with fluorouracil or dacarbazine in the treatment of advanced carcinoid tumors: Eastern Cooperative Oncology Group Study E1281. J Clin Oncol. 2005;23(22): 4897-4904

89. Eriksson B, Kloppel G, Krenning E, et al. Consensus guidelines for the management of patients with digestive neuroendocrine tumors well-differentiated jejunal-ileal tumor/carcinoma. Neuroendocrinology. 2008;87(1):8-19.

90. Ahlman H, Wangberg B, Jansson S, et al. Interventional treatment of gastrointestinal neuroendocrine tumours. Digestion. 2000;62 Suppl 1: 59-68.

91. Kam BL, Teunissen JJ, Krenning EP, et al. Lutetium-labelled peptides for therapy of neuroendocrine tumours. Eur J Nucl Med Mol Imaging. 2012;39 Suppl 1:S103-S112.

92. Florio T. Molecular mechanisms of the antiproliferative activity of somatostatin receptors (SSTRs) in neuroendocrine tumors. Front Biosci. 2008; 13:822-840.

93. Chua YJ, Michael M, Zalcberg JR, et al. Antitumor effect of somatostatin analogs in neuroendocrine tumors. J Clin Oncol. 2010;28(3): e41-e42.

94. Schmid HA. Pasireotide (SOM230): development, mechanism of action and potential applications. Mol Cell Endocrinol. 2008;286(1-2): 69-74.

95. Strosberg J, Kvols L. Antiproliferative effect of somatostatin analogs in gastroenteropancreatic neuroendocrine tumors. World J Gastroenterol. 2010;16(24):2963-2970.

96. Colao A, Petersenn S, Newell-Price J, et al. A 12-month phase 3 study of pasireotide in Cushing's disease. N Engl J Med. 2012;366(10): 914-924.

97. Yao JC. Neuroendocrine tumors. Molecular targeted therapy for carcinoid and islet-cell carcinoma. Best Pract Res Clin Endocrinol Metab. 2007;21(1):163-172.

98. Kulke MH, Lenz HJ, Meropol NJ, et al. Activity of sunitinib in patients with advanced neuroendocrine tumors. J Clin Oncol. 2008;26(20): 3403-3410.

99. Hobday TJ, Rubin J, Holen K. MC044h, a Phase II trial of sorafenib in patients (pts) with metastatic neuroendocrine tumors (NET): a Phase II consortium (P2C) study. J Clin Oncol. 2007;25(18S):4504.
100. Pavel ME, Bartel C, Heuck F. Open-label, non-randomized, multicenter phase II study evaluating the angiogenesis inhibitor PTK787/ ZK222584 (PTK/ZK) in patients with advanced neuroendocrine carcinomas (NEC). J Clin Oncol. 2008;26 Suppl:14684.

101. Hobday TJ, Holen K, Donehower R. A Phase II trial of gefitinib in patients (pts) with progressive metastatic neuroendocrine tumors (NET): a Phase II consortium (P2C) study. J Clin Oncol. 2006;24(18S):189s.

102. Duran I, Kortmansky J, Singh D, et al. A Phase II clinical and pharmacodynamic study of temsirolimus in advanced neuroendocrine carcinomas. Br J Cancer. 2006;95(9):1148-1154.

103. Yao JC, Phan AT, Chang DZ, et al. Efficacy of RAD001 (everolimus) and octreotide LAR in advanced low- to intermediate-grade neuroendocrine tumors: results of a phase II study. J Clin Oncol. 2008;26(26): 4311-4318.

104. Pavel ME, Hainsworth JD, Baudin E, et al. Everolimus plus octreotide long-acting repeatable for the treatment of advanced neuroendocrine tumours associated with carcinoid syndrome (RADIANT-2): a andomized, placebo-controlled, phase 3 study. Lancet. 2011;378(9808):2005-2012.

105. Pape UF, Perren A, Niederle B, et al. ENETS consensus guidelines for the management of patients with neuroendocrine neoplasms from the jejuno-ileum and the appendix including goblet cell carcinomas. Neuroendocrinology. 2012;95(2):135-156.

106. Plockinger U, Couvelard A, Falconi M, et al. Consensus guidelines for the management of patients with digestive neuroendocrine tumours: well-differentiated tumour/carcinoma of the appendix and goblet cell carcinoma. Neuroendocrinology. 2008;87(1):20-30.

107. Caplin M, Sundin A, Nillson O, et al. ENETS consensus guidelines for the management of patients with digestive neuroendocrine neoplasms: colorectal neuroendocrine neoplasms. Neuroendocrinology. 2012; 95(2):88-97.

108. Kaltsas GA, Besser GM, Grossman AB. The diagnosis and medical management of advanced neuroendocrine tumors. Endocr Rev. 2004;25(3):458-511.

109. Basu B, Sirohi B, Corrie P. Systemic therapy for neuroendocrine tumours of gastroenteropancreatic origin. Endocr Relat Cancer. 2010;17(1):R75-R90.

110. Modlin IM, Kidd M, Drozdov I, Siddique ZL, Gustafsson BI. Pharmacotherapy of neuroendocrine cancers. Expert Opin Pharmacother. 2008;9(15):2617-2626.

111. Yao JC, Lombard-Bohas C, Baudin E, et al. Daily oral everolimus activity in patients with metastatic pancreatic neuroendocrine tumors after failure of cytotoxic chemotherapy: a phase II trial. J Clin Oncol. 2010;28(1):69-76.

112. Taupenot L, Harper KL, O'Connor DT. The chromograninsecretogranin family. $N$ Engl J Med. 2003;348(12):1134-1149.

113. Bajetta E, Ferrari L, Martinetti A, et al. Chromogranin A, neuron specific enolase, carcinoembryonic antigen, and hydroxyindole acetic acid evaluation in patients with neuroendocrine tumors. Cancer. 1999;86(5):858-865.

114. Seregni E, Ferrari L, Bajetta E, Martinetti A, Bombardieri E. Clinical significance of blood chromogranin A measurement in neuroendocrine tumours. Ann Oncol. 2001;12 Suppl 2:S69-S72.

115. Lawrence B, Gustafsson BI, Kidd M, Pavel M, Svejda B, Modlin IM. The clinical relevance of chromogranin A as a biomarker for gastroenteropancreatic neuroendocrine tumors. Endocrinol Metab Clin North Am. 2011;40(1):111-134.

116. Oberg K, Stridsberg M. Chromogranins as diagnostic and prognostic markers in neuroendocrine tumours. Adv Exp Med Biol. 2000; 482:329-337.

117. Boudreaux JP, Klimstra DS, Hassan MM, et al. The NANETS consensus guideline for the diagnosis and management of neuroendocrine tumors: well-differentiated neuroendocrine tumors of the jejunum, ileum, appendix, and cecum. Pancreas. 2010;39(6): 753-766. 
118. Janson ET, Holmberg L, Stridsberg M, et al. Carcinoid tumors: analysis of prognostic factors and survival in 301 patients from a referral center. Ann Oncol. 1997;8(7):685-690.

119. Kulke MH, Siu LL, Tepper JE, et al. Future directions in the treatment of neuroendocrine tumors: consensus report of the National Cancer Institute Neuroendocrine Tumor clinical trials planning meeting. J Clin Oncol. 2011;29(7):934-943.

120. Williams ED. Histological Typing of Tumors of the Enodcrine System. Berlin, Germany: Springer-Verlag; 1980.

121. Ehehalt F, Saeger HD, Schmidt CM, Grutzmann R. Neuroendocrine tumors of the pancreas. Oncologist. 2009;14(5):456-467.
122. Jensen RT. Pancreatic endocrine tumors: recent advances. Ann Oncol. 1999;10 Suppl 4:170-176.

123. Jensen R. Endocrine tumors of the gastrointestinal tract and pancreas. In: Kasper DL, Fauci AS, Braunwald E, Longo DL, JL Jameson JL, editors. Harrison's Principles of Internal Medicine. 17th ed. New York, NY: McGraw-Hill; 2008:2.

124. Schimmack S, Svejda B, Lawrence B, Kidd M, Modlin IM. The diversity and commonalities of gastroenteropancreatic neuroendocrine tumors. Langenbecks Arch Surg. 2011;396(3):273-298.

\section{Publish your work in this journal}

Gastrointestinal Cancer: Targets and Therapy is an international, peer-reviewed, open access journal focusing on gastro-intestinal cancer research, identification of therapeutic targets and the optimal use of preventative and integrated treatment interventions to achieve improved outcomes, enhanced survival and quality of life for the cancer patient. The manuscript management system is completely online and includes a very quick and fair peer-review system. Visit http://www.dovepress.com/testimonials.php to read real quotes from published authors.

Submit your manuscript here: http://www.dovepress.com/gastro-intestinal-cancer-targets-and-therapy-journal 